\title{
FAKTOR-FAKTOR YANG BERHUBUNGAN DENGAN PERILAKU PEMBERIAN ASI EKSKLUSIF PADA BAYI USIA 0-6 BULAN DI WILAYAH KERJA PUSKESMAS KENALI BESAR KOTA JAMBI TAHUN 2017
}

\author{
Putri Dewi Anggraini \\ Akademi Kebidanan Jakarta Mitra Sejahtera Jambi \\ email: $\underline{\mathrm{Pu} \text { 3dewi@yahoo.com }}$
}

\begin{abstract}
Abstrak
Kesadaran masyarakat memberikan ASI kepada bayinya menunjukkan grafik yang meningkat. Sepanjang tahun 2004-2008 cakupan pemberian ASI eksklusif meningkat dari 59.9\% menjadi $62.2 \%$. Namun setelah itu grafik tidak mengalami peningkatan bahkan cenderung mengalami penurunan. Penelitian ini merupakan penelitian yang bersifat analitik dengan menggunakan pendekatan cross sectional. Penelitian ini dilakukan di Wilayah Kerja Puskesmas Kenali Besar Kota Jambi. Waktu penelitian dilakukan pada bulan Juni tahun 2017. Populasi dalam penelitian ini berjumlah 197 orang. Sampel diambil secara purposive sampling. Pengumpulan data dilakukan dengan cara pengisian kuesioner. Analisis yang digunakan dalam penelitian ini adalah analisis univariat dan bivariat. Tujuan penelitian ini untuk mengetahui faktor-faktor yang berhubungan dengan perilaku pemberian ASI Ekslusif pada bayi usia 0-6 bulan di wilayah Kerja Puskesmas Kenali Besar Kota Jambi Tahun 2017. Hasil penelitian menunjukkan bahwa ada hubungan antara pengetahuan ibu, peran keluarga dan persepsi ibu dengan perilaku pemberian ASI eksklusif pada bayi usia 0-6 bulan di Wilayah Kerja Puskesmas Kenali Besar Kota Jambi tahun 2017.
\end{abstract}

Kata kunci : pengetahuan, persepsi, peran keluarga, ASI eksklusif

\begin{abstract}
Awareness of the community giving breast milk to the baby shows an increasing graph. Throughout 2004-2008, exclusive breastfeeding coverage increased from 59.9\% to 62.2\%. But after that the graph did not increase even tended to decrease. This research is an analytic research using cross sectional approach. This research was conducted at Working Area of Puskesmas Kenali Besar Kota Jambi. The study was conducted in June of 2017. The population in this study amounted to 197 people. Samples were taken by purposive sampling. The data were collected using questionnaires by filling out questionnaires. The analysis used in this research is univariate and bivariate analysis. The purpose of this study to determine the factors associated with exclusive breastfeeding behavior in infants aged 0 6 months in the work area Puskesmas Kenali Besar Kota Jambi Year 2017. The results showed that there was a correlation between mother's knowledge of family role and mother's perception with exclusive breastfeeding behavior in infants aged 0-6 months in the Working Area of Puskesmas Kenali Besar Kota Jambi in 2017.
\end{abstract}

Keywords : knowledge, perception, family role, exclusive breast milk

\section{PENDAhuluan}

Kesadaran masyarakat memberikan ASI kepada bayinya menunjukkan grafik yang meningkat. Sepanjang tahun 2004-2008 cakupan pemberian ASI eksklusif meningkat dari $59.9 \%$ menjadi $62.2 \%$. Namun setelah itu grafik tidak mengalami peningkatan bahkan cenderung mengalami penurunan (Maryunani, 2012).

Berdasarkan data Riset Kesehatan Dasar (Riskesdas) tahun 2013, menunjukkan pemberian ASI Eksklusif untuk bayi yang berusia $<6$ bulan secara global kurang dari 40\%. Dengan demikian angka global dari ASI Ekslklusif Indonesia masih lebih tinggi jika 
dibandingkan dengan angka global. Hal ini disebabkan kesadaran masyarakat dalam mendorong peningkatan pemberian ASI masih relatif rendah. Padahal tidak ada yang bisa menandingi kualitas ASI bahkan susu formula sekalipun (Maryunani, 2012).

Pemberian ASI sejak lahir akan menjamin seorang bayi berkembang menjadi anak yang cerdas, karena kandungan asam lemak omega 3 dan omega 6 yang terkandung di dalam ASI sangat berperan dalam penyusunan sel-sel otak. Namun pada kenyataannya rasio jumlah ibu yang tidak dapat menyusui bayinya dibandingkan dengan yang dapat menyusui sangat kecil, artinya hampir semua ibu dapat menyusui bayinya dengan baik. Walaupun begitu dukungan dari seluruh anggota keluarga sangat diperlukan agar ibu dapat menyusui bayinya secara penuh (Maryunani, 2012).

Air Susu Ibu (ASI) merupakan jenis makanan awal terbaik bagi bayi. Ibu memutuskan memberikan ASI pada bayi merupakan hal yang sangat tepat, karena seluruh fungsi zat gizi yang dibutuhkan bayi terdapat pada ASI. (Eveline dan Djamaludin, 2010).

Gencarnya promosi susu formula menjadi penyebab menurunnya jumlah bayi yang mendapat ASI Eksklusif. Banyak ibu yang tidak percaya diri dengan manfaat dari kandungan ASI akibat pengaruh iklan yang mengidealkan kandungan zat gizi terdapat dalam susu formula. Penyebab umum kegagalan pemberian ASI eksklusif adalah minimnya pengetahuan ilmu ibu tentang ASI Eksklusif dan menyusui, ibu bekerja dan tidak ada dukungan dari keluarga, teknik menyusui yang tidak tepat dan mitos ASI encer tidak baik untuk bayi (Mulyani, 2013).

Kendala yang sering menjadi alasan ibu tidak memberikan ASI eksklusif, yaitu produksi ASI kurang, ibu kurang memahami tata laksana laktasi yang benar, ibu ingin menyusui kembali setelah bayi diberi formula, kelainan ibu ( puting ibu lecet, puting ibu luka, payudara bengkak, engorgement, mastitis dan abses, ibu hamil lagi padahal masih menyusui, dan ibu bekerja) (Partiwi, 2009).

Pentingnya ASI eksklusif memang harus menjadi perhatian dan tanggung jawab orang tua. Orang tua juga harus mulai menyadari akan dampak pada bayi jika ASI eksklusif ini tidak diberikan pada bayi dengan maksimal. Pertumbuhan bayi pada usia 0-6 bulan bisa sangat terhambat dan kemungkinan besar juga bayi tidak sehat. Perhatian akan pentingnya ASI eksklusif juga harus berasal dari lingkungan sekitar, agar pemberian ASI eksklusif di terapkan dalam kebiasaan atau budaya yang harus di lestarikan. Karena susu formula yang diandalkan sebagai pengganti ASI eksklusif tidak akan sebaik ASI. Banyak sekali kandungan susu formula yang tidak terdapat pada ASI, lebih memiliki fungsi menyeluruh pada bayi sedangkan susu formula hanya memacu sebagian saja (Harnowo, 2012).

Peran keluarga menjadi utama karena ibu bukanlah pelaku tunggal yang bertanggung jawab dalam pemberian ASI Eksklusif. Keluarga terdekat dalam hal ini adalah suami merupakan faktor dominan dalam memberikan dukungan pada ibu dan bayi. Beragam penelitian berhasil membuktikan terdapatnya hubungan yang bermakna antara peran keluarga terdekat dengan keberhasilan pemberian ASI eksklusif. Ayah memiliki peran dalam mendukung keberhasilan pemberian ASI eksklusif. Begitupun keluarga terdekat lainnya terutama orang tua baik dari pihak ibu maupun ayah sang bayi (Rahayu, 2013).

Ibu sangat dianjurkan untuk memberikan ASI kepada bayi secara eksklusif selama 6 bulan pertama. ASI terbukti memiliki bakteri yang menguntungkan dan zat-zat yang dibutuhkan oleh bayi untuk membentuk mikroflora usus yang penting untuk sistem daya tahan tubuh bayi. Bayi yang disusui eksklusif selama 6 bulan memiliki daya perlindungan yang lebih tinggi terhadap penyakit infeksi dibandingan bayi dengan ASI eksklusif selama 6 bulan (Mulyani, 2013).

Tanpa adanya dukungan suami akan mempunyai cakupan terendah dalam pemberian ASI eksklusif jika dibandingkan dengan puskesmas lainnya di Kota Jambi yaitu pada tahun 2015 yaitu pada semester 1 sebanyak 31 bayi $(20,4 \%)$ dan semester 2 sebanyak 21 bayi $(25,6 \%)$. Sedangkan tahun 2016 yaitu pada semester 1 sebanyak 21 bayi $(25,6 \%)$ dan semester 2 sebanyak 32 bayi $(21,1 \%)$. Sedangkan kejadian diare pada bayi di Puskesmas Kenali Besar mengalami peningkatan setiap tahunnya yaitu pada tahun 2015 sebanyak 55 bayi dan tahun 2016 sebanyak 105 bayi.

Survey awal yang telah dilakukan peneliti mengenai pemberian ASI eksklusif di 
Puskesmas Kenali Besar Kota Jambi terhadap 10 ibu yang memiliki bayi, menunjukkan bahwa sebesar 7 ibu mengatakan tidak mengetahui kandungan dalam ASI, menganggap ASI dan susu formula memiliki komposisi kandungan yang sama serta keluarga tidak mengingatkan ibu untuk memberikan ASI secara Eksklusif. Sedangkan 3 ibu mengatakan mengetahui kandungan dalam ASI, menganggap ASI merupakan makanan yang paling penting diberikan pada bayi dan keluarga selalu mengingatkan ibu untuk memberikan ASI secara eksklusif.

Tujuan penelitian ini adalah untuk mengetahui faktor-faktor yang berhubungan dengan perilaku pemberian ASI Eksklusif di wilayah kerja puskesamas Kenali Besar Kota Jambi tahun 2017.

\section{METODE PENELITIAN}

Penelitian ini merupakan penelitian yang bersifat analitik dengan menggunakan pendekatan cross sectional yang bertujuan untuk mempelajari faktor-faktor yang berhubungan dengan perilaku pemberian ASI eksklusif pada bayi usia 0-6 bulan di Wilayah Kerja Puskesmas Kenali Besar Kota Jambi tahun 2017. Penelitian ini menggunakan dua variabel terdiri dari variabel independen yaitu pengetahuan, persepsi dan peran keluarga, sedangkan variabel dependen yaitu pemberian ASI eksklusif.

Penelitian ini dilakukan di Wilayah Kerja Puskesmas Kenali Besar Kota Jambi pada bulan Januari tahun 2017. Populasi dalam penelitian ini adalah seluruh ibu yang memiliki bayi usia 6-12 bulan pada bulan Januari 2017 yang bertempat tinggal di Wilayah Kerja Puskesmas Kenali Besar Kota Jambi yaitu sebanyak 197 orang. Sampel dipilih dengan teknik purposive sampling.
Data yang dibutuhkan dalam penelitian ini yaitu data mengenai faktorfaktor yang berhubungan dengan perilaku pemberian ASI eksklusif pada bayi usia 0-6 bulan di Wilayah Kerja Puskesmas Kenali Besar Kota Jambi tahun 2017. Pengumpulan data dalam penelitian ini dengan pengisian kuesioner. Kuesioner yang digunakan adalah pertanyaan terstruktur untuk mengambil data mengenai faktor-faktor yang berhubungan dengan perilaku pemberian ASI eksklusif pada bayi usia 0-6 bulan di Wilayah Kerja Puskesmas Kenali Besar Kota Jambi tahun 2017. Analisis data dilakukan secara Univariat dan Analisa Bivariat.

\section{HASIL DAN PEMBAHASAN}

Tabel 1. Distribusi Responden Berdasarkan Pengetahuan, Persepsi, Peran Keluarga Tentang Pemberian ASI Eksklusif Pada Bayi Usia 0-6 Bulan

\begin{tabular}{l|c|c|c}
\hline $\begin{array}{c}\text { Karakteristik } \\
\text { responden }\end{array}$ & Indikator & Jumlah & $\begin{array}{c}\text { Prosentase } \\
(\%)\end{array}$ \\
\hline Pengetahuan & Baik & 7 & 10.8 \\
& Cukup & 36 & 55.4 \\
& Kurang & 22 & 33.8 \\
Baik & & \\
Persepsi & Negatif & 40 & 61.5 \\
& Positif & 25 & 38.5 \\
Peran & Baik & 23 & 35.4 \\
keluarga & Kurang & 42 & 64.6 \\
& Baik & & \\
Pemberian & Diberika & 21 & 32.3 \\
ASI & $\mathrm{n}$ & 44 & 67.7 \\
Ekslklusif & Tidak & & \\
& diberikan & & \\
\hline & & & \\
\hline
\end{tabular}


Tabel 2. Distribusi Hubungan Pengetahuan Ibu Dengan Perilaku Pemberian ASI Eksklusif Pada Bayi Usia 0-6 Bulan

\begin{tabular}{|c|c|c|c|c|c|c|c|c|}
\hline & \multirow{3}{*}{ Pengetahuan } & \multicolumn{4}{|c|}{ Pemberian ASI Eksklusif } & \multirow{2}{*}{\multicolumn{2}{|c|}{ Total }} & \multirow{3}{*}{ P-value } \\
\hline & & \multicolumn{2}{|c|}{$\begin{array}{c}\text { Tidak } \\
\text { Diberikan }\end{array}$} & \multicolumn{2}{|c|}{ Diberikan } & & & \\
\hline & & $f$ & $\%$ & $f$ & $\%$ & $f$ & $\%$ & \\
\hline 1 & Kurang Baik & 20 & 90.9 & 2 & 9.1 & 22 & 100 & \multirow{4}{*}{0.004} \\
\hline 2 & Cukup & 22 & 61.1 & 14 & 38.9 & 36 & 100 & \\
\hline 3 & Baik & 2 & 28.6 & 5 & 71.4 & 7 & 100 & \\
\hline & TOTAL & 44 & 67.7 & 21 & 32.3 & 65 & 100 & \\
\hline
\end{tabular}

Berdasarkan Tabel 2 diperoleh informasi bahwa dari 22 responden dengan pengetahuan kurang baik yang tidak memberikan ASI eksklusif pada bayi usia 0-6 bulan sebanyak 90,9\%. Sedangkan dari 7 responden dengan pengetahuan baik didapat $28,6 \%$ tidak memberikan ASI eksklusif pada bayi usia 0-6 bulan.
Dari hasil uji statistik chi-square diperoleh nilai $p$ value $0,004(\mathrm{p}<0,05)$ dengan demikian dapat disimpulkan bahwa ada hubungan antara pengetahuan ibu dengan perilaku pemberian ASI eksklusif pada bayi usia 0-6 bulan di Wilayah Kerja Puskesmas Kenali Besar Kota Jambi.

Tabel 3. Distribusi Hubungan Persepsi Ibu Dengan Perilaku Pemberian ASI Eksklusif Pada Bayi Usia 0-6 Bulan di Wilayah Kerja Puskesmas Kenali Besar Kota Jambi Tahun 2017

\begin{tabular}{|c|c|c|c|c|c|c|c|c|}
\hline & \multirow{3}{*}{ Persepsi } & \multicolumn{4}{|c|}{ Pemberian ASI Eksklusif } & \multirow{2}{*}{\multicolumn{2}{|c|}{ Total }} & \multirow{3}{*}{ P-value } \\
\hline & & \multicolumn{2}{|c|}{$\begin{array}{c}\text { Tidak } \\
\text { Diberikan }\end{array}$} & \multicolumn{2}{|c|}{ Diberikan } & & & \\
\hline & & $\mathrm{f}$ & $\%$ & $\mathrm{~F}$ & $\%$ & $\mathrm{f}$ & $\%$ & \\
\hline 1 & Negatif & 32 & 80.0 & 8 & 20.0 & 40 & 100 & \\
\hline 2 & Positif & 12 & 48.0 & 13 & 52.0 & 25 & 100 & 0.016 \\
\hline & TOTAL & 44 & 67.7 & 21 & 32.3 & 65 & 100 & \\
\hline
\end{tabular}

Dari 40 responden dengan persepsi negatif yang tidak memberikan ASI eksklusif pada bayi usia 0-6 bulan sebanyak $80,0 \%$. Sedangkan dari 25 responden dengan persepsi positif didapat $48,0 \%$ tidak memberikan ASI eksklusif pada bayi usia 0-6 bulan. Dari hasil uji statistik chi-square diperoleh nilai $p$ value
$0,016 \quad(\mathrm{p}<0,05)$ dengan demikian dapat disimpulkan bahwa ada hubungan antara persepsi ibu dengan perilaku pemberian ASI eksklusif pada bayi usia 0-6 bulan di Wilayah Kerja Puskesmas Kenali Besar Kota Jambi.

Tabel 4. Distribusi Hubungan Keluarga Dengan Perilaku Pemberian ASI Eksklusif Pada Bayi Usia 0-6 Bulan di Wilayah Kerja Puskesmas Kenali Besar Kota Jambi Tahun 2017

\begin{tabular}{|c|c|c|c|c|c|c|c|c|}
\hline & \multirow{3}{*}{ Peran Keluarga } & \multicolumn{4}{|c|}{ Pemberian ASI Eksklusif } & \multirow{2}{*}{\multicolumn{2}{|c|}{ Total }} & \multirow{3}{*}{ P-value } \\
\hline & & \multicolumn{2}{|c|}{$\begin{array}{c}\text { Tidak } \\
\text { Diberikan }\end{array}$} & \multicolumn{2}{|c|}{ Diberikan } & & & \\
\hline & & $\mathrm{f}$ & $\%$ & $\mathrm{~F}$ & $\%$ & $\mathrm{f}$ & $\%$ & \\
\hline 1 & Kurang Baik & 34 & 81.0 & 8 & 19.0 & 42 & 100 & \multirow{3}{*}{0.005} \\
\hline 2 & Baik & 10 & 43.5 & 13 & 56.5 & 23 & 100 & \\
\hline & TOTAL & 44 & 67.7 & 21 & 32.3 & 65 & 100 & \\
\hline
\end{tabular}


Berdasarkan tabel 4 diperoleh informasi baahwa dari 42 responden dengan peran keluarga kurang baik yang tidak memberikan ASI eksklusif pada bayi usia 0-6 bulan sebanyak $81,0 \%$. Sedangkan dari 23 responden dengan pengetahuan baik didapat 43,5\% tidak memberikan ASI eksklusif pada bayi usia 0-6 bulan. Dari hasil uji statistik chisquare diperoleh nilai $p$ value $0,005(\mathrm{p}<0,05)$ dengan demikian dapat disimpulkan bahwa ada hubungan antara peran keluarga dengan perilaku pemberian ASI eksklusif pada bayi usia 0-6 bulan di Wilayah Kerja PsEuskesmas Kenali Besar Kota Jambi.

\section{Gambaran Pengetahuan Ibu Tentang Perilaku Pemberian ASI Eksklusif Pada Bayi Usia 0-6 Bulan di Wilayah Kerja Puskesmas Kenali Besar Kota Jambi Tahun 2017}

Berdasarkan hasil analisis data, 7 responden $(10,8 \%)$ mempunyai pengetahuan yang baik tentang pemberian ASI eksklusif pada bayi usia 0-6 bulan, sebanyak 36 responden $(55,4 \%)$ mempunyai pengetahuan cukup tentang pemberian ASI eksklusif pada bayi usia $0-6$ bulan dan sebanyak 22 responden $(33,8 \%)$ mempunyai pengetahuan kurang baik tentang pemberian ASI eksklusif pada bayi usia 0-6 bulan.

Hasil jawaban mayoritas responden tidak mengetahui apa akibat bila bayi tidak diberi ASI, tidak mengetahui cara memperbanyak ASI dan tidak mengetahui hal yang perlu dipertimbangkan dalam menentukan frekuensi pemberian ASI eksklusif.

Penelitian yang telah dilakukan sejalan dengan penelitian Marhama (2012) mengenai hubungan pengetahuan dan persepsi ibu terhadap pemberian ASI eksklusif pada bayi usia 0-6 bulan di Puskesmas Pasawahan, menunjukkan bahwa, menunjukkan bahwa sebesar $61.9 \%$ ibu memiliki pengetahuan cukup tentang pemberian ASI eksklusif pada bayi usia $0-6$ bulan.

Menurut Notoatmodjo (2010), pengetahuan merupakan hasil "tahu", dan ini terjadi setelah orang melakukan pengindraan terhadap suatu objek tertentu. Pengindraan terjadi melalui pancaindra manusia, yakni indra penglihatan, indra pendengaran, indra penciuman, perasa dan peraba. Sebagian besar pengetahuan manusia diperoleh melalui mata dan telinga. Pengetahuan yang dicakup di dalam domain kognitif yang mempunyai 6 tingkat yaitu tahu, memahami, aplikasi, analisis, sintesis, dan evaluasi.

Pada penelitian ini sebagian besar responden yang memiliki pengetahuan cukup, disebabkan responden pada umumnya belum tahu dan belum memahami dengan baik tentang pemberian ASI eksklusif. Hal ini dapat dikarenakan responden tidak mencari informasi baik dari elektronik ataupun media massa tentang pemberian ASI eksklusif.

Adapun responden memiliki pengetahuan yang baik dikarenakan responden masih mengingat suatu materi yang telah dipelajari sebelumnya mengenai pemberian ASI eksklusif. Materi yang mereka dapat berupa penyuluhan kesehatan yang dilakukan oleh tenaga kesehatan dan informasi-informasi yang didapat dari media massa ataupun media elektronik. Sehingga sebagian kecil responden dapat menjawab pertanyaan yang diberikan dengan baik dan benar.

Upaya-upaya yang perlu dilakukan untuk meningkatkan pengetahuan responden tentang pemberian ASI eksklusif adalah dilakukannya penyuluhan kesehatan mengenai pemberian ASI eksklusif, menjelaskan manfaat dan keuntungan jika ibu melakukan pemberian ASI eksklusif kepada bayi 0-6 bulan.

\section{Gambaran Persepsi Ibu Tentang Perilaku Pemberian ASI Eksklusif Pada Bayi Usia 0- 6 Bulan di Wilayah Kerja Puskesmas Kenali Besar Kota Jambi Tahun 2017}

Berdasarkan hasil analisis data, diperoleh informasi 25 responden $(38,5 \%)$ memiliki persepsi positif tentang pemberian ASI eksklusif pada bayi usia 0-6 bulan, dan sebanyak 40 responden $(61,5 \%)$ memiliki persepsi negatif terhadap pemberian ASI eksklusif pada bayi usia 0-6 bulan.

Hasil jawaban menunjukkan bahwa mayoritas responden menjawab Sangat Setuju. Dikatakan persepsi positif bila skor jawaban $\geq$ mean dan dikategorikan persepsi negatif bila skor jawaban < mean. Nilai mean adalah 28,12 .

Penelitian yang telah dilakukan sejalan dengan penelitian Marhama (2012) mengenai hubungan pengetahuan dan persepsi ibu terhadap pemberian ASI eksklusif pada bayi usia 0-6 bulan di Puskesmas Pasawahan, ang menyatakan bahwa sebesar $67,4 \%$ ibu 
memiliki persepsi negatif tentang pemberian ASI eksklusif pada bayi usia 0-6 bulan.

Persepsi merupakan suatu proses yang didahului oleh proses penginderaan, yaitu merupakan proses diterimanya stimulus oleh individu melalui alat indera atau juga disebut proses sensoris. Namun proses itu tidak berhenti begitu saja, melainkan stimulus tersebut diteruskan dan proses selanjutnya merupakan proses persepsi. Karena itu proses persepsi tidak dapat lepas dari proses penginderaan dan proses penginderaan merupakan proses pendahulu dari proses persepsi (Walgito, 2010).

Responden yang memiliki persepsi negatif terhadap pemberian ASI eksklusif dikarenakan responden memiliki pandangan bahwa ASI eksklusif memiliki nutrisi yang sangat penting bagi bayi tetapi untuk menambah asupan nutrisi yang lebih baik maka diselingin dengan memberikan susu formula, karena mereka menganggap susu formula juga sangat penting diberikan pada bayi 0-6 bulan sehingga ASI dan susu formulan yang diberikan pada bayi 0-6 bulan bisa saling melengkapi.

Upaya yang harus dilakukan untuk membentuk persepsi yang positif terhadap pemberian ASI eksklusif yaitu diberikan informasi yang lebih mendalam mengenai pemberian ASI eksklusif, meyakinkan kepada ibu bahwa pemberian ASI eksklusif tidak bisa disertai dengan pemberian susu formulan dan nutrisi di dalam ASI merupakan nutrisi yang sangat penting untuk pertumbuhan dan perkembangan bayi dan nutrisi tersebut tidak ada di dalam susu formula. Selain itu petugas kesehatan mengajak responden untuk melakukan diskusi bersama dalam membahas permasalahan pemberian ASI eksklusif agar ibu lebih memahami permasalahan pemberian ASI eksklusif.

\section{Gambaran Peran Keluarga Tentang Perilaku Pemberian ASI Eksklusif Pada Bayi Usia 0-6 Bulan di Wilayah Kerja Puskesmas Kenali Besar Kota Jambi Tahun 2017}

Berdasarkan analisis data diperoleh informasi bahwa sebanyak 23 responden $(35,4 \%)$ mempunyai peran keluarga yang baik tentang pemberian ASI eksklusif pada bayi usia $0-6$ bulan, dan sebanyak 42 responden $(64,6 \%)$ mempunyai peran keluarga kurang baik tentang pemberian ASI eksklusif pada bayi usia 0-6 bulan. Kategori peran keluarga dikatakan baik jika skor jawaban $\geq$ mean dan dikategorikan peran keluarga kurang baik bila skor jawaban < mean. Nilai mean adalah 6,14.

Dukungan keluarga adalah keberatan, kesedihan, kepedulian dari orang-orang yang dapat diandalkan, menghargai dan menyayangi kita. dukungan keluarga sebagai adanya kenyamanan, perhatian, penghargaan atau menolong orang dengan sikap menerima kondinya, dukungan keluarga tersebut diperoleh dari individu maupun kelompok (Jhonson, 2009).

Pada penelitian ini banyak responden yang memiliki dukungan keluarga yang kurang baik tentang pemberian ASI Eksklusif, hal ini dikarenakan suami masih belum memahami lebih mendalam tentang pemberian ASI Eksklusif tersebut, sehingga keluarga takut responden mengalami kesulitan dalam memberikan ASI Eksklusif. Selain itu keluarga tidak pernah mencari informasi tentang pemberian ASI Eksklusif baik dari media massa ataupun media elektronik.

Peran keluarga menjadi utama karena ibu bukanlah pelaku tunggal yang bertanggungjawab dalam pemberian ASI Eksklusif. Keluarga terdekatlah dalam hal ini adalah suami yang faktor dominan dalam memberikan dukungan pada ibu dan bayi.

Upaya-upaya yang perlu dilakukan untuk meningkatkan dukungan keluarga responden menjadi lebih baik tentang pemberian ASI Eksklusif adalah dilakukannya penyuluhan kesehatan mengenai ASI Eksklusif secara mendalam, menjelaskan manfaat dan keuntungan jika ibu memberikan ASI Eksklusif

Gambaran Perilaku Pemberian ASI Eksklusif Pada Bayi Usia 0-6 Bulan di Wilayah Kerja Puskesmas Kenali Besar Kota Jambi Tahun 2017

Berdasarkan hasil analisis data, diperoleh informasi bahwa sebanyak 21 responden $(32,3 \%)$ memberikan ASI eksklusif pada bayi usia 0-6 bulan, dan sebanyak 44 responden $(67,7 \%)$ tidak memberikan ASI eksklusif pada bayi usia 0-6 bulan.

Dari penjelasan, diketahui bahwa responden sebagian besar tidak memberikan ASI Eksklusif, disebabkan responden belum memahami dengan baik tentang ASI Eksklusif. Hal ini sesuai dengan pendapat 
Notoatmodjo (2007), untuk berperilaku sehat diperlukan pengetahuan yang tepat, sikap, persepsi, motivasi dan dukungan suami untuk berperilaku sehat. Pengetahuan dan dukungan suami sangat berpengaruh terhadap perilaku menjalankan aktivitas untuk mencapai tujuan. Masalah yang menyebabkan seseorang sulit termotivasi untuk berperilaku sehat adalah karena perubahan perilaku dari yang tidak sehat menjadi sehat tidak menimbulkan dampak langsung secara tepat, bahkan mungkin tidak berdampak apa-apa.

Kendala yang sering menjadi alasan ibu tidak memberikan ASI eksklusif, yaitu produksi ASI kurang, ibu kurang memahami tata laksana laktasi yang benar, ibu ingin menyusui kembali setelah bayi diberi formula (relaktasi), bayi terlanjur mendapatkan prelakteal feeding (pemberian air gula/dekstrosa, susu formula pada hari-hari pertama kelahiran), kelainan ibu: puting ibu lecet, puting ibu luka, payudara bengkak, engorgement, mastitis dan abses, ibu hamil lagi padahal masih menyusui, dan ibu bekerja.

Upaya-upaya yang perlu agar responden memberikan ASI Eksklusif adalah dilakukannya penyuluhan kesehatan mengenai ASI Eksklusif, menjelaskan dengan menggunakan bahasa yang mudah dimengerti agar responden dapat memahami dengan baik dan juga dengan cara memberikan leaflet, dan kegiatan promotif lainnya seperti melakukan diskusi bersama responden.

\section{Hubungan Pengetahuan Ibu Dengan Perilaku Pemberian ASI Eksklusif Pada Bayi Usia 0-6 Bulan di Wilayah Kerja Puskesmas Kenali Besar Kota Jambi Tahun 2017}

Berdasarkan bahwa dari 22 responden dengan pengetahuan kurang baik yang tidak memberikan ASI eksklusif pada bayi usia 0-6 bulan sebanyak 90,9\%. Sedangkan dari 7 responden dengan pengetahuan baik didapat 28,6\% tidak memberikan ASI eksklusif pada bayi usia $0-6$ bulan

Dari hasil uji statistik chi-square diperoleh nilai $p$ value $0,004(\mathrm{p}<0,05)$ dengan demikian dapat disimpulkan bahwa ada hubungan antara pengetahuan ibu dengan perilaku pemberian ASI eksklusif pada bayi usia 0-6 bulan di Wilayah Kerja Puskesmas Kenali Besar Kota Jambi.

Pengetahuan merupakan hasil tahu dari tahu, dan ini terjadi setelah orang melakukan pengindraan terhadap suatu objek tertentu. Pengindraan terjadi melalui panca indra manusia, yakni indra penglihatan, pendengaran, penciuman, rasa dan raba. Sebagian besar pengetahuan manusia diperoleh melalui mata dan telinga (Notoatmodjo, 2007).

Penelitian yang telah dilakukan sejalan dengan penelitian Marhama (2012) mengenai hubungan pengetahuan dan persepsi ibu terhadap pemberian ASI eksklusif pada bayi usia 0-6 bulan di Puskesmas Pasawahan, menunjukkan bahwa sebagian besar 41 ibu $(67,2 \%)$ memiliki pengetahuan cukup dan adanya hubungan pengetahuan ibu dengan pemberian ASI eksklusif pada bayi usia 0-6 bulan dengan $p$-value 0,017 .

Dari penjelasan, sebagian besar responden memiliki pengetahuan cukup, disebabkan responden pada umumnya belum tahu dan belum memahami dengan baik tentang pemberian ASI eksklusif pada bayi usia 0-6 bulan. Hal ini dikarenakan kesadaran dan minat yang masih rendah untuk mencari tambahan informasi untuk meningkatkan pengetahuannya, disamping itu juga dapat dikarenakan sudah pernah diberikan penyuluhan kesehatan oleh responden tersebut mengenai pemberian ASI eksklusif pada bayi usia $0-6$ bulan tetapi responden lupa atau tidak ingat dengan informasi yang pernah didapat.

Upaya-upaya yang perlu dilakukan untuk meningkatkan pengetahuan responden tentang pemberian ASI eksklusif pada bayi usia 0-6 bulan adalah dilakukannya pendidikan kesehatan kepada responden mengenai pemberian ASI eksklusif pada bayi usia 0-6 bulan, menjelaskan dengan menggunakan bahasa yang mudah dimengerti agar responden dapat memahami dengan baik dan juga dengan cara memberikan leaflet, brosur, dan kegiatan promotif lainnya seperti melakukan diskusi bersama responden.

Selain itu diharapkan responden untuk aktif mencari informasi tentang pemberian ASI eksklusif pada bayi usia 0-6 bulan agar menambah pengetahuan responden yang kurang baik. Jika hanya pasif saja, maka akan berdampak kurang baik pada tingkat pengetahuan mereka. Bagi responden yang telah mempunyai pengetahuan yang baik, harus selalu dipertahankan dan diingat materimateri yang telah diberikan sebelumnya, agar mereka mengetahui pemberian ASI eksklusif pada bayi usia 0-6 bulan. 


\section{Hubungan Persepsi Ibu Dengan Perilaku Pemberian ASI Eksklusif Pada Bayi Usia 0- 6 Bulan di Wilayah Kerja Puskesmas Kenali Besar Kota Jambi Tahun 2017}

Berdasarkan hasil penelitian bahwa dari 40 responden dengan persepsi negatif yang tidak memberikan ASI eksklusif pada bayi usia 0-6 bulan sebanyak $80,0 \%$. Sedangkan dari 25 responden dengan persepsi positif didapat $48,0 \%$ tidak memberikan ASI eksklusif pada bayi usia 0-6 bulan.

Dari hasil uji statistik chi-square diperoleh nilai $p$ value $0,016(\mathrm{p}<0,05)$ dengan demikian dapat disimpulkan bahwa ada hubungan antara persepsi ibu dengan perilaku pemberian ASI eksklusif pada bayi usia 0-6 bulan di Wilayah Kerja Puskesmas Kenali Besar Kota Jambi.

Persepsi merupakan suatu proses yang didahului oleh proses penginderaan, yaitu merupakan proses diterimanya stimulus oleh individu melalui alat indera atau juga disebut proses sensoris. Namun proses itu tidak berhenti begitu saja, melainkan stimulus tersebut diteruskan dan proses selanjutnya merupakan proses persepsi. Karena itu proses persepsi tidak dapat lepas dari proses penginderaan dan proses penginderaan merupakan proses pendahulu dari proses persepsi (Walgito, 2010).

Persepsi merupakan pengalaman tentang objek, peristiwa, atau hubunganhubungan yang diperoleh dengan menyimpulkan informasi dan menafsirkannya. Persepsi adalah memberikan makna kepada stimulus. Persepsi berbeda dengan sensasi meskipun keduanya berhubungan (Notoatmodjo, 2010).

Penelitian yang telah dilakukan sejalan dengan penelitian Marhama (2012) mengenai hubungan pengetahuan dan persepsi ibu terhadap pemberian ASI eksklusif pada bayi usia 0-6 bulan di Puskesmas Pasawahan, menunjukkan bahwa mayoritas sebanyak 45 ibu (73,8\%) memiliki persepsi negatif dan adanya hubungan persepsi ibu dengan pemberian ASI eksklusif pada bayi usia 0-6 bulan dengan $p$-value 0,008 .

Berdasarkan penjelasan terlihat bahwa responden mempunyai persepsi negatif terhadap pemberian ASI eksklusif pada bayi usia 0-6 bulan karena menganggap tidak perlu melakukan pemberian ASI eksklusif pada bayi usia 0-6 bulan karena nutrisi dalam susu formula juga penting bagi tubuh bayi. Persepsi tersebut dikarenakan responden tidak memiliki informasi lebih mendalam tentang pemberian ASI eksklusif pada bayi usia 0-6 bulan, sehingga hanya dengan informasi secara umum membentuk suatu pandangan negatif terhadap pemberian ASI eksklusif pada bayi usia 0-6 bulan.

Oleh karena itu, upaya-upaya yang perlu dilakukan untuk membentuk persepsi positif terhadap pemberian ASI eksklusif pada bayi usia 0-6 bulan adalah diberikannya penyuluhan mengenai pemberian ASI eksklusif pada bayi usia 0-6 bulan, dengan penyuluhan tersebut memungkinkan responden membuat keputusan yang logis dan matang terhadap pemberian ASI eksklusif pada bayi usia 0-6 bulan.

Upaya selanjutnya yaitu dengan diberikan pendidikan kesehatan berkaitan dengan persepsi yang baik dan tidak baik tentang pemberian ASI eksklusif pada bayi usia 0-6 bulan dengan cara memberikan pengetahuan dan menanamkan nilai-nilai serta persepsi positif. Hal ini dapat dilakukan dengan memberikan leaflet dan informasi seperti spanduk dalam upaya memberikan pengetahuan secara luas agar terbentuk persepsi yang positif.

\section{Hubungan Peran Keluarga Dengan Perilaku Pemberian ASI Eksklusif Pada Bayi Usia 0-6 Bulan di Wilayah Kerja Puskesmas Kenali Besar Kota Jambi Tahun 2017}

Berdasarkan hasil penelitian bahwa dari 42 responden dengan peran keluarga kurang baik yang tidak memberikan ASI eksklusif pada bayi usia 0-6 bulan sebanyak $81,0 \%$. Sedangkan dari 23 responden dengan pengetahuan baik didapat $43,5 \%$ tidak memberikan ASI eksklusif pada bayi usia 0-6 bulan.

Dari hasil uji statistik chi-square diperoleh nilai $p$ value $0,005(\mathrm{p}<0,05)$ dengan demikian dapat disimpulkan bahwa ada hubungan antara peran keluarga dengan perilaku pemberian ASI eksklusif pada bayi usia 0-6 bulan di Wilayah Kerja Puskesmas Kenali Besar Kota Jambi.

Dari penjelasan diatas, menunjukkan bahwa masih banyaknya responden yang memiliki peran keluarga kurang baik. Hal ini 
dikarenakan keluarga belum memahami dengan baik tentang perilaku pemberian ASI eksklusif pada bayi usia 0-6 bulan dan belum pernah diberikan penyuluhan kesehatan oleh petugas kesehatan mengenai perilaku pemberian ASI eksklusif pada bayi usia 0-6 bulan. Padahal dengan adanya dukungan keluarga, maka responden dapat rutin melakukan perilaku pemberian ASI eksklusif pada bayi usia 0-6 bulan. Jika hanya sasaran pada responden saja yang selalu diberi informasi, sementara keluarga kurang pembinaan dan pendekatan, keluarga kadang malah menyarankan memberikan susu formula karena faktor ketidaktahuan dan tidak ada komunikasi untuk saling memberikan pengetahuan.

Upaya-upaya yang perlu dilakukan untuk meningkatkan peran keluarga mengenai perilaku pemberian ASI eksklusif pada bayi usia 0-6 bulan yaitu dengan diberikan pendidikan kesehatan berkaitan dengan motivasi dari intrinsik dan ekstrinsik dalam perilaku pemberian ASI eksklusif pada bayi usia 0-6 bulan dengan cara memberikan pengetahuan dan menanamkan nilai-nilai serta persepsi positif. Hal ini dapat dilakukan dengan memberikan leaflet dan informasi seperti spanduk dalam upaya memberikan pengetahuan secara luas agar terbentuk sikap yang positif dan memotivasi keluarga untuk membantu responden dalam memberikan ASI Eksklusif.

\section{KESIMPULAN DAN SARAN}

Adanya hubungan antara pengetahuan, peran keluarga, persepsi ibu dengan perilaku pemberian ASI eklsklusif di wilayah kerja puskesmas Kenali Besar Kota Jambi Tahun 2017.

Diharapkan agar petugas kesehatan khususnya bidan untuk terus melakukan promosi dan poster dalam memberikan penyuluhan tentan pencapaian ASI Ekslklusif, menjelaskan dengan menggunakan bahasa yang mudah dimengerti agar respon dapat memahami dengan baik serta mengajak keluarga untuk berperan aktif dalam memberikan informasi dan membantu ibu dalam memberikan ASI Esklusif.

\section{DAFTAR PUSTAKA}

Eveline \& Djamaludin. 2010. Panduan Pintar Merawat Bayi dan Balita. Jakarta : Penerbit Wahyu Media.

Harnowo. 2012. Hanya 33,6\% Bayi di Indonesia yang Dapat ASI Eksklusif. Dalam http://Hanya-33,6\%-Bayi-diIndonesia-yang-Dapat-ASI-

Eksklusif.htm. (diakses tanggal 07 Februari 2015).

Jhonson. 2009. Keperawatan Keluarga : Plus Contoh Askep Keluarga. Yogyakarta: Penerbit Nuha Medika.

Kodrat, Laksono. 2010. Dahsyatnya ASI dan Laktasi Untuk Kecerdasan Buah Hati Anda. Yogyakarta: Penerbit Media Baca.

Kristiyanasari, Weni. 2011. Asuhan Keperawatan Neonatus dan Anak. Yogyakarta: Penerbit Nuha Medika.

Marhama, 2012. Hubungan Pengetahuan Dan Persepsi Ibu Terhadap Pemberian Asi Eksklusif Pada Bayi Usia 0-6 bulan di Puskesmas Pasawahan dalam http.//pemberian-asi-eksklusif.htm (diakses tanggal 6 Februari 2015)

Marimbi, Hanum. 2010. Tumbuh Kembang, Status Gizi dan Imunisasi Dasar Pada Balita. Yogyakarta: Penerbit Nuha Medika.

Maryunani, Anik. 2012. Ilmu Kesehatan Anak Dalam Kebidanan. Jakarta : Penerbit Trans Info Media.

- 2012. Inisiasi Menyusu Dini, ASI Ekslusif dan Manajemen Laktasi. Jakarta : Penerbit CV. Trans Info Media.

Mulyani, Nina Siti. 2013. ASI dan Pedoman Ibu Menyusui. Yogyakarta: Penerbit Nuha Medika.

Notoatmodjo, Soekidjo. 2007. "Promosi Kesehatan Teori Dan Aplikasi". Jakarta :Penerbit PT. Rineka Cipta. 
Putri Dewi Anggraini, Faktor-Faktor Yang Berhubungan Dengan Perilaku Pemberian Asi Eksklusif Pada Bayi Usia 0-6 Bulan Di Wilayah Kerja Puskesmas Kenali Besar Kota Jambi Tahun 2017

2010. Perilaku

Kesehatan dan Ilmu Perilaku. Jakarta: Penerbit PT. Rineka Cipta.

Partiwi, Ayu Nyoman \& Jeanne Purnawati, 2009. Kendala Pemberian ASI eksklusif. Dalam http://www.idai.or.id/asi/artikel.asp?q $=201057102916$ (diakses tanggal 07 Februari 2015)

Priyono, Yunisa. 2010. Merawat Bayi Tanpa Baby Sitter. Yogyakarta: Penerbit Med Press.

Proverawati, Atikah dkk. 2010. Kapita Selekta ASI dan Menyusui. Yogyakarta: Penerbit Nuha Medika.

Purwanti, Hubertin Sri. 2010. Penerapan ASI Eksklusif Buku Saku Untuk Bidan. Jakarta: Penerbit Buku Kedokteran EGC.

Rahayu, Indira. 2013. Pemberian ASI Sebagai Langkah Utama Pencegahan Diare. Dalam http://www.manjur.net/20/03/2013/pe mberian-asi-sebagai-langkah-utamapencegahan-diare. (diakses tanggal 07 Februari 2015).

Walgito, Bimo. 2010. Pengantar Psikologi Umum. Yogyakarta: Penerbit CV. Andi. 